\title{
Pertinencia del Marketing digital en las empresas de Aburrá Sur
}

Cómo citar este artículo / To reference this article / Comment citer cet article / Para citar este artigo:

Trejos-Gil, C. A. (2020). Pertinencia del Marketing digital en las empresas de Aburrá Sur. Revista Escuela de Administración de Negocios, (88), 81-101. DOI: https://doi.org/10.21158/01208160.n88.2020.2696

\section{Resumen}

Debido a las altas tasas de mortalidad de las pequeñas y medianas empresas -pymes- en Colombia, donde, en el 2016, se tuvieron cifras cercanas al $70 \%$ de liquidación en el primer año y del $20 \%$ en el segundo, existe la necesidad de crear mecanismos, herramientas y alternativas que ayuden a las pymes a no cerrar de forma prematura. Este trabajo propone analizar la actualidad del Marketing digital en 13 pymes inscritas a la Cámara de Comercio Aburrá Sur (CCAS) de Antioquia, Colombia, escogidas de forma aleatoria. Se implementó una metodología de enfoque cuantitativo con análisis exploratorio, descriptivo y correlación de variables con el fin de validar la fiabilidad del instrumento. Los resultados indican que de las 13 pymes inscritas en la CCAS, el 23,1 $\%$ considera un gasto el Marketing digital. A pesar de que el 46,2 \% no lo considera costoso, el 53,8 \% se encarga — por sí mismos — del Marketing digital, apenas el 30,8 \% miden sus actividades en Marketing digital y el $100 \%$ está interesado en recibir capacitaciones al respecto. Por tanto, se concluye que, si bien los empresarios conocen el Marketing digital, no lo aplican de forma adecuada, lo hacen de manera empírica y no invierten en él.

Palabras clave: Marketing; Marketing digital; pymes; pymes en Colombia; redes sociales; tecnologías de la información.

\footnotetext{
${ }^{1}$ Magister en Dirección Estratégica (Especialidad gerencia) - Universidad Internacional Iberoamericana; MBA. Máster Internacional en Administración y Dirección de Empresas - Universidad Europea del Atlántico. Especialista en Alta Gerencia - Universidad de Medellín. Profesional en Publicidad - Universidad Católica de Manizales. Integrante del grupo de investigación URBANITAS de la Universidad Católica Luis Amigó. ORCID: https://orcid.org/0000-0002-6769-3396
} 


\section{Abstract}

\section{Relevance of digital Marketing in the companies of Aburrá Sur}

Due to the high mortality rates of small and medium-sized enterprises (SMEs) in Colombia in 2016, where close to $70 \%$ liquidated during their first year of operation and $20 \%$ during their second year, raises the necessity to create mechanisms, tools, and alternatives that help SMEs not to close down prematurely. This document proposes to analyze the current status of digital Marketing in 13 SMEs chosen at random and that are registered with the Chamber of Commerce of Aburrá Sur (CCAS) in Antioquia, Colombia. We implemented a methodology of quantitative approach with exploratory- descriptive analysis and correlation of variables in order to validate the reliability of the instrument. The results indicate that out of the 13 SMEs registered with the CCAS, $23.1 \%$ consider digital Marketing to be an expense. Despite the fact that $46.2 \%$ do not consider it costly, $53.8 \%$ are in charge -by themselves- of digital Marketing, only 30.8\% measure their activities in digital Marketing, and $100 \%$ are interested in receiving training in this area. Therefore, it is concluded that, although entrepreneurs know about digital Marketing, they do not apply it properly,; instead, they do it empirically and do not invest in it.

Keywords: Marketing; digital Marketing; SMEs; SMEs in Colombia; social networks; information technologies.

\section{Resumo}

\section{A pertinência do Marketing digital nas empresas de Aburrá Sur}

Devido às altas taxas de mortalidade das pequenas e médias empresas - PYMES - na Colômbia, onde, em 2016, ocorreram cifras próximas a $70 \%$ de liquidação no primeiro ano e de $20 \%$ no segundo, há necessidades de criar mecanismos, ferramentas e alternativas que ajudem as PYMES a não fecharem prematuramente. Este trabalho propõe analisar a situação atual do Marketing digital em 13 PYMES cadastradas na Câmara do Comércio Aburrá Sur (CCAS) de Antioquia, Colômbia, escolhidas de forma aleatória. Implementou-se uma metodologia de abordagem quantitativa com análise exploratória e descritiva e correlação de variáveis para validar a confiabilidade do instrumento. Os resultados indicam que das 13 PYMES cadastradas no CCAS, 23,1\% consideram o Marketing digital uma despesa. Embora 46,2\% não o considerem caro, 53,8\% são responsáveis pelo Marketing digital por conta própria, apenas 30,8\% medem suas atividades no Marketing digital e 100\% têm interesse em receber treinamentos sobre isso. Portanto, conclui-se que, embora os empreendedores conheçam o Marketing digital, não o aplicam de maneira adequada, fazem empiricamente e não investem nele.

Palavras-chave: Marketing; Marketing digital; PYMES; PYMES na Colômbia; redes sociais; tecnologias da informação. 


\section{Pertinence du Marketing numérique dans les entreprises de la región d'Aburrá Sur}

Résumé

En raison des taux de faillites élevés des petites et moyennes entreprises - PME - de Colombie, où, en 2016, plus de $70 \%$ d'entre elles ont été contraintes à la fermeture dès la première année d'exercice et $20 \%$ lors de leur seconde année d'existence, il est urgent et vital de créer des mécanismes, des outils et des alternatives aidant les PME à ne pas perricliter prématurément. Dans cet article nous analyserons la situation actuelle du Marketing numérique de 13 PME choisies au hasard et enregistrées à la chambre de commerce d'Aburrá Sur (CCAS), dans la région d'Antioquia, en Colombie. Une méthodologie quantitative a été mise en œuvre se fondant sur une analyse exploratoire et descriptive avec corrélation des variables afin de valider la fiabilité de l'instrument. Les résultats indiquent que sur les 13 PME inscrites au CCAS, 23,1\% considèrent le Marketing numérique comme une dépense superflue et, bien que $46,2 \%$ considèrent cet outil abordable financièrement, que $53,8 \%$ de ces PME réalisent elles-même leur propre Marketing digital, et que seulement 30,8\% mesurent les résultats de leurs activités de Marketing digital, 100\% d'entre elles se disent intéressés à recevoir des formations en Marketing digital. Nous concluerons notre étude en montrant que bien que les entrepreneurs connaissent le Marketing numérique, nombreux sont ceux qui l'utilisent de maniére empirique, incorrectement, en n'y investissant pas suffisamment.

Mots-clés: Marketing; Marketing numérique; PME; PME colombienne; réseaux sociaux; technologie de l'information. 


\section{Introducción}

\subsection{Marketing: una evolución determinante de gran soporte promocional}

El Marketing es un proceso social en el cual se ejecuta todo un conjunto de operaciones, procesos y procedimientos que un producto o un servicio debe atravesar desde la fabricación o surgimiento hasta el consumidor final. Actualmente, el Marketing hace parte del $\mathrm{ADN}$ de las empresas que compiten $\mathrm{y}$ ofrecen valor a sus clientes reales y potenciales (Andrade, 2016).

En su libro Marketing, Kotler (2016) lo define de la siguiente manera:

actividad encaminada a atraer y administrar relaciones redituables con los clientes; se refiere a la creación de valor para los clientes. Por lo tanto, como primer paso, la compañía debe comprender plenamente a los consumidores y al mercado en que opera. (pp. 4-6)

En una entrevista concedida a Axon (2012), Phillip Kotler menciona tres tipos de Marketing:

Tabla 1. Evolución del Marketing según Phillip Kotler

\begin{tabular}{|l|l|l|}
\hline \multicolumn{1}{|c|}{ Marketing 1.0 } & \multicolumn{1}{|c|}{ Marketing 2.0 } & \multicolumn{1}{c|}{ Marketing 3.0 } \\
\hline${ }^{*}$ Marketing centrado en el producto & ${ }^{*}$ Marketing centrado en el consumidor & ${ }^{*}$ Marketing centrado en los valores \\
\hline${ }^{*}$ Vende productos & ${ }^{*}$ Satisface y retiene a los consumidores & ${ }^{*}$ Crea un mundo mejor \\
\hline * Comunicadores con necesidades básicas & $\begin{array}{l}{ }^{*} \text { Consumidor más inteligente con } \\
\text { mente y corazón }\end{array}$ & $\begin{array}{l}\text { * Ser humano integral, con mente, } \\
\text { corazón y espíritu }\end{array}$ \\
\hline * Valor económico & ${ }^{*}$ Valor en la persona & ${ }^{*}$ Valor en el medio ambiente \\
\hline${ }^{*}$ Medios tradicionales & $\begin{array}{l}{ }^{*} \text { Medios tradicionales + medios } \\
\text { interactivos }\end{array}$ & * Medios interactivos \\
\hline${ }^{*}$ Unidireccionales & ${ }^{*}$ Bidireccionales & ${ }^{*}$ Multidireccionales \\
\hline
\end{tabular}

Fuente. Elaboración propia con base en Axon, 2012.

- Marketing 1.0. Tiene un enfoque netamente orientado al producto. Su importancia es la venta del mismo bien o servicio y sus consumidores se definen por sus necesidades básicas —escala de necesidades de Maslow_; prima el valor económico; las comunicaciones y la publicidad se realizan por medios tradicionales y se da la comunicación unidireccional, es decir, de la empresa al consumidor (véase la Tabla 1 ).

- Marketing 2.0. Se centra en el consumidor, su objetivo es satisfacerlo y retenerlo, pues es más inteligente si se asume que tiene mente y corazón; el valor se centra en la persona, sus comunicaciones se enfocan en medios tradicionales e interactivos y es bidireccional: empresa-cliente, cliente-empresa.

- Marketing 3.0. Se centra en los valores; su enfoque está enmarcado en crear un mundo mejor, el cliente se comprende como un ser humano integral con mente, corazón y espíritu; el valor se fundamenta en el cuidado del medio ambiente, las comunicaciones son netamente por medios interactivos y la comunicación con sus clientes son de carácter multidireccional. 
El Marketing de carácter social, centrado en el consumidor, tiene relación directa con el ámbito digital, en vista de que son todas aquellas actividades en pro de la construcción de marca como, por ejemplo, el Marketing directo (Trejos, 2008), ya que son todas aquellas aplicaciones y estrategias enfocadas por medios digitales con el fin de generar contacto directo con los públicos objetivos a través de las diferentes plataformas y herramientas digitales en las que existan aspectos de conectividad.

Del mismo modo, la comunicación bidireccional — Marketing 2.0—, apoyada en redes sociales en función de promoción de marca, productos o servicios, propende a posicionar la marca (Londoño, Mora y Valencia, 2018) y generar rentabilidad para los empresarios. Ahora bien, internet es el medio idóneo como herramienta por el cual es posible que la información se comparta de forma instantánea a través de herramientas tecnológicas tales como el correo electrónico, aplicaciones móviles o redes sociales, entre otras (Andrade, 2016).

\subsection{El correo electrónico como herramienta táctica del Marketing digital}

Una campaña de e-mail Marketing es una táctica digital muy efectiva para convertir clientes potenciales en clientes reales (Merodio, 2016), y luego en clientes fieles. Esta táctica consiste en el envío de un e-mail personalizado sobre una base de datos previamente segmentada, a fin de trasladar información general, novedades, productos o servicios de característica promocional. Su principal ventaja y éxito es la posibilidad de segmentar el público al realizar envíos pequeños bien divididos que se adapten a las necesidades del público al que se dirige. Sin embargo, el correo electrónico es asíncrono: emisor y receptor no interactúan de forma simultánea, por tanto, el feedback no es inmediato y puede tardar minutos, horas o días. La actividad del e-mail Marketing debe basarse en valor y confianza para el usuario, por tanto, los autores presentan tres tipos de e-mails (véase la Tabla 2) y dos tipos de acciones de esta misma herramienta (Vila y Küster, 2004).

En Oportunidades y amenazas del e-mail Marketing Vila y Küster (2004) afirman que el correo electrónico permite el intercambio de información o de productos entre distintos tipos de agentes, tales como el B2C, B2B, B2A-C2A y C2B-C2C.

Tabla 2. Tipos de e-mail como herramienta del Marketing digital

\begin{tabular}{|l|l|}
\hline \multicolumn{1}{|c|}{ Tipo } & \multicolumn{1}{c|}{ Descripción } \\
\hline E-mail directo & $\begin{array}{l}\text { * Envío de un mensaje promocional con forma de un e-mail desde el propio gestor } \\
\text { de correo a una lista de contactos personales o profesionales. Está en relación con el } \\
\text { mailing. }\end{array}$ \\
\hline Mailing & $\begin{array}{l}\text { * Es la difusión masiva directa de información publicitaria, propias o no propias de una } \\
\text { marca. Estas se ven recompensadas con clics, mayor número de clientes fidelizados y } \\
\text { aumento de ventas. }\end{array}$ \\
\hline E-mail de retención & $\begin{array}{l}\text { * Cuando el objetivo principal es generar un impacto de largo plazo en la relación con } \\
\text { los contactos, estos e-mails suelen tomar forma de newsletters o de un sitio de noticias } \\
\text { variadas con información de la empresa, aunque también puede incluir una sección de } \\
\text { ofertas o ventas. }\end{array}$ \\
\hline $\begin{array}{l}\text { Publicidad en los e-mails } \\
\text { de otras entidades }\end{array}$ & $\begin{array}{l}\text { * En la mayoría de los casos este se emplea cuando no se tiene una base de datos propia. } \\
\text { Consiste en utilizar los newsletters de otras personas y pagarles para poner publicidad } \\
\text { en los e-mails que envían a sus suscriptores. }\end{array}$ \\
\hline $\begin{array}{l}\text { Newsletters o boletín } \\
\text { informativo }\end{array}$ & $\begin{array}{l}\text { Es una de las fórmulas más efectivas para la generación de leads. Se utiliza para informar } \\
\text { y fidelizar a los clientes o interesados, destacar acciones de relaciones públicas (RP), } \\
\text { publicitar productos o servicios, publicar novedades de la empresa y del sector a un bajo } \\
\text { costo y en muy poco tiempo. Solo se envían a quienes desean suscribirse previamente. }\end{array}$ \\
\hline
\end{tabular}

Fuente. Elaboración propia con base en Vila y Küster, 2004. 
En el B2C (business to consumer) el correo electrónico pone en contacto a la empresa y el consumidor —en España esta opción es limitada a un 0,43 \%-. En el $\mathrm{B} 2 \mathrm{~B}$ (business to business) el correo electrónico pone en contacto a una empresa con otra; en España es el más común en un 99,57\%. Con elB2A-C2A (business) costumer to administrations) el correo electrónico pone en contacto a la empresa/consumidores y la administración. Los C2B (consumer to business) y $\mathrm{C} 2 \mathrm{C}$ (consumer to consumer) no son tan usuales como las anteriores, y se refiere a que los consumidores se relacionan con la empresa bien sea para expresar su satisfacción, o bien quejas, críticas y calificaciones, entre otros.

\subsection{Contexto de las redes sociales como aporte para las compañías}

En cuanto a redes sociales, se trata de un estudio realizado por IAB Spain (2015) que muestra la categorización de las redes sociales más usadas; en las figuras 1 y 2 se aprecian las primeras seis redes sociales más usadas en este país europeo y en el mundo.

Figura 1. Utilización de las distintas redes sociales por las empresas en España

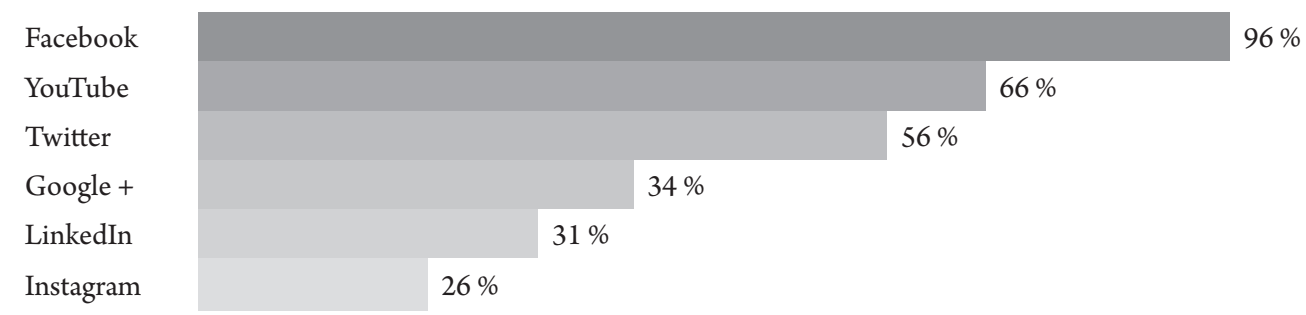

Fuente. IAB Spain, 2015.

Figura 2. Utilización de las distintas redes sociales por las empresas en el mundo

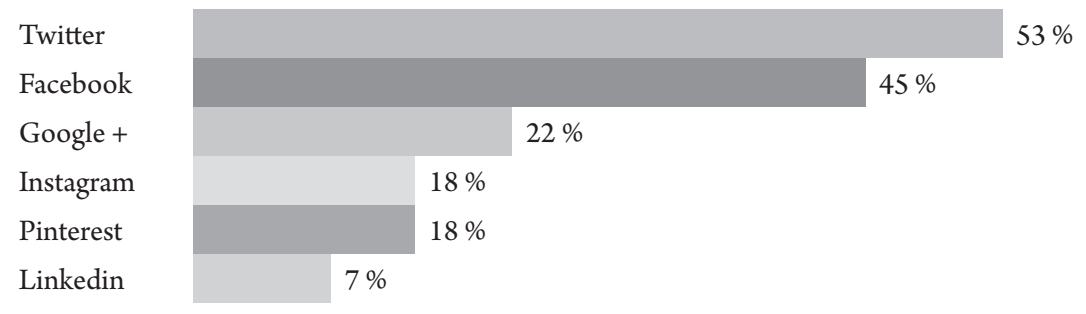

Fuente. Nieto, 2016.

Algunas empresas y sus marcas ejercen cada vez más presencia en las redes sociales mediante publicaciones promocionales, otras optan por la generación de contenidos relevantes para sus públicos de preferencia, de manera que cada red social tiene su propia característica (véase la Tabla 3). Sin embargo, no todas las empresas tienen las mismas redes sociales, así como tampoco son todas las redes sociales útiles para cualquier tipo de negocio; es necesario, primero, tener en cuenta la razón esencial de la empresa y, de esta forma, elegir la más adecuada para la marca. Antes que nada, se debe tener presente que las redes sociales se identifican por dos grandes tipos: unas son las redes sociales horizontales — generalistasy otras las verticales - especializadas- (Ramón y Segovia, 2016). 
Tabla 3. Principales redes sociales para empresas y su aplicación

\begin{tabular}{|c|c|c|}
\hline Red social & Descripción & Aplicación según tipo de empresas \\
\hline Facebook & $\begin{array}{l}\text { Fan page: difusión de información } \\
\text { promocional y divulgación de } \\
\text { contenido. Permite obtener } \\
\text { mediciones relevantes sobre el alcance } \\
\text { de publicaciones, seguidores, impacto } \\
\text { y comentarios. }\end{array}$ & Todo tipo de empresas \\
\hline Instagram & $\begin{array}{l}\text { Red social gráfica y de video, } \\
\text { catalogada en redes multimedia (Adán } \\
\text { et al., 2015). }\end{array}$ & $\begin{array}{l}\text { Empresas que basan sus publicaciones } \\
\text { en fotografías y microvideos; empresas } \\
\text { textiles, de cocina, accesorios, maquillajes, } \\
\text { decoraciones para hogar, fotógrafos, etc. }\end{array}$ \\
\hline Twitter & $\begin{array}{l}\text { Microblogging como parte de redes de } \\
\text { comunicación (Adán et al., 2015). }\end{array}$ & $\begin{array}{l}\text { Empresas generadoras de información } \\
\text { constante, sobre todo, noticiosas y periódicas. }\end{array}$ \\
\hline YouTube & $\begin{array}{l}\text { Red para compartir videos y redes } \\
\text { multimedia (Adán et al., 2015). }\end{array}$ & Todo tipo de empresas \\
\hline LinkedIn & $\begin{array}{l}\text { Redes de diferentes medios e idiomas, } \\
\text { redes de comunicación. }\end{array}$ & Todo tipo de empresas \\
\hline Pinterest & $\begin{array}{l}\text { Redes de diferentes medios e idiomas, } \\
\text { redes de comunicación. }\end{array}$ & $\begin{array}{l}\text { Empresas que basen sus publicaciones } \\
\text { en fotografías, imágenes, ilustraciones e } \\
\text { infografías para empresas textiles, cocina, } \\
\text { accesorios, maquillajes, decoraciones para } \\
\text { hogar, fotógrafos, artistas y diseñadores, etc. }\end{array}$ \\
\hline
\end{tabular}

Fuente. Elaboración propia.

Las redes sociales horizontales son aquellas redes sociales dirigidas a todo tipo de público sin que se centren en alguna temática en particular, por, ejemplo, Facebook, Instagram, Twitter, Google+, etc.; las verticales son todo lo contrario: manejan temáticas específicas —salud, educación, deportes, viajes, etc.—. En las redes sociales verticales se diferencia entre las que son de ocio y las profesionales, entendiendo como ocio todas aquellas de entretenimiento, como, por ejemplo, Tripadvisor, Minube, Laneros, etc., y como profesionales Linkedin, Xing y Viadeo, entre otras (Ramón y Segovia, 2016).
Según el sector, cada red social tiene un uso específico a nivel mundial (Nieto, 2016) (véase la Figura 3). Entre las redes sociales más usadas por las empresas se encuentran tanto las verticales como las horizontales; lo que las diferencia es su razón de ser y el objeto social de la organización, aunque hay empresas que usan cualquier red social — sin ser lo más recomendable—, surge más efecto realizar publicaciones de manera concienzuda y de forma planificada (Londoño et al., 2018). 
Figura 3. Utilización de las distintas redes sociales de las empresas en el mundo por sector

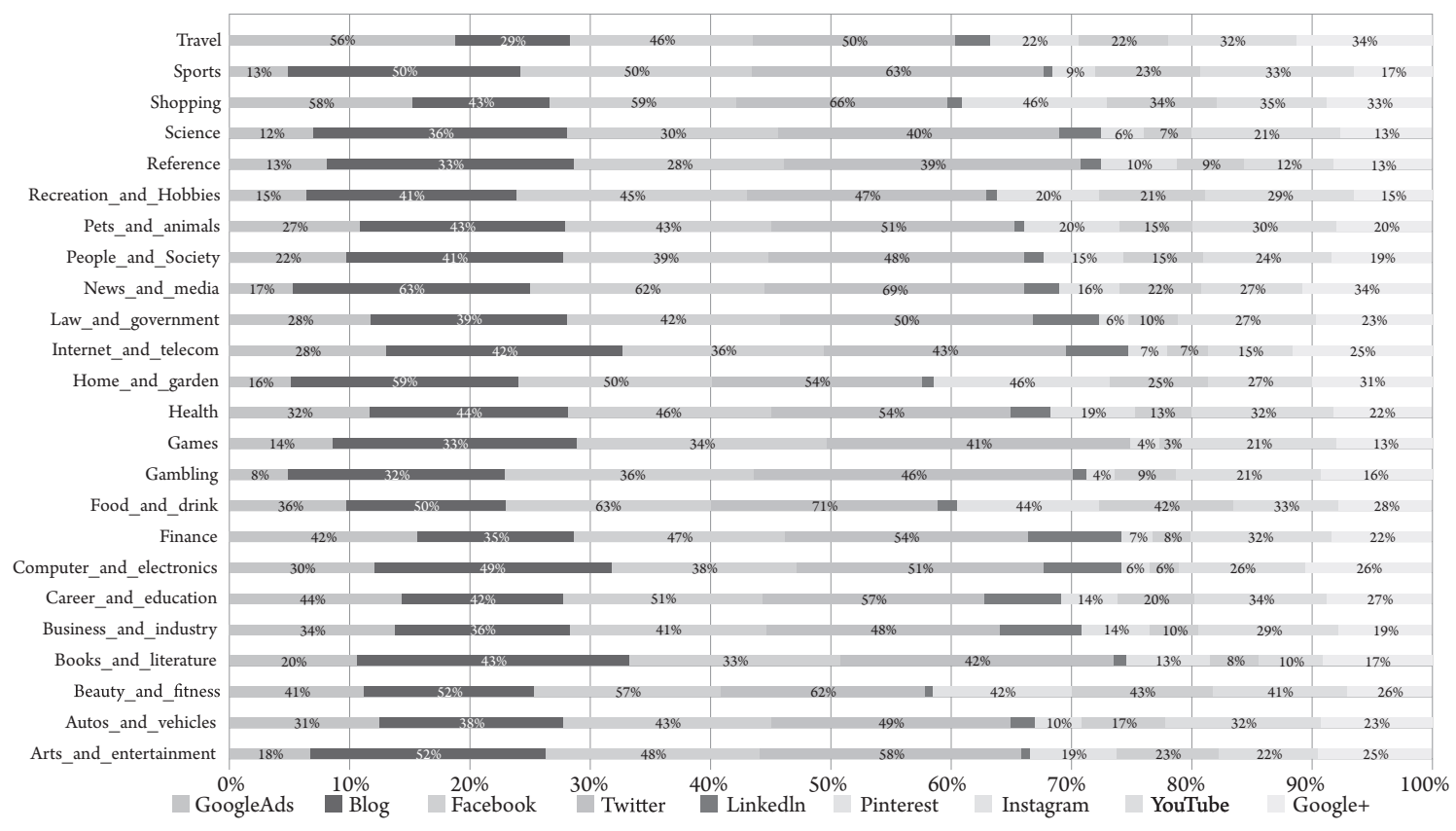

Fuente. Elaboración propia con base en Nieto, 2016.

Como se aprecia en la figura 3 , en términos generales, la red social más usada por las empresas, independiente de su categoría o sector económico, es Twitter, con un promedio del $53 \%$, sumándose a la segunda y tercera posición Facebook - $45 \%$ - y Blog — $43 \%$-, respectivamente, todas enmarcadas como horizontales/generalistas. Se destaca el alto uso de diferentes redes sociales en los sectores shopping, food and drink, beauty and fitness, news and media $y$ home and garden como los cinco con mayor variedad de redes sociales, en promedio.

El panorama en Colombia es consecuente con lo descrito. La firma Invamer, en septiembre del 2018, realizó para la revista Dinero un estudio que identifica cuáles son las marcas más activas y que gestionan mejor sus redes sociales. Para ese estudio se definieron siete variables a analizar, entre ellas Facebook, Instagram, Twitter, Blog y otras redes sociales, además de servicio al cliente, variedades de contenidos e influencia y participación. Lo interesante del estudio es el ranking de 100 marcas que mejor gestionan sus redes, además de las nueve variables que se ponderaron para medir el valor único de cada una de las siete variables. Entre estas se midieron los sectores de cuidado personal, bebidas, motos, ropa accesorios y calzado, supermercados-, tiendas por departamento, cervezas, café y chocolate, alimentos, helados, chocolatinas y golosinas, licores, lugares de comida rápida, tecnología y electrodomésticos, automóviles, aerolíneas, teléfonos celulares, servicios de telefonía celular, aseo, pañales y papel higiénico y catálogos, entre otros (Ranking de marcas, 27 de septiembre de 2018).

Es innegable la necesidad de las empresas de usar internet y las redes sociales como canal de comunicación directa con sus públicos objetivos (Londoño et al., 2018), pero también se evidencia que se debe escoger la red social adecuada para cada empresa en particular, así como realizar su debida planeación en la generación de contenidos.

Ahora bien, en Colombia se presenta hoy una situación compleja relacionada con la alta tasa de fracaso de las empresas. Se han desarrollado diferentes estudios año tras año y los resultados no son alentadores; el 
diario El Tiempo publica en su sección de economía y negocios que, cada año, se liquida un promedio de 137 empresas que pertenecen a todos los sectores de la economía, y en los últimos diez años se iniciaron procesos de liquidación de 1366 empresas, de los cuales el $72 \%$ ya culminó su proceso de liquidación (Rueda, 2017).

Por otro lado, Confecámaras, en cuanto ente regulador de las cámaras de comercio en Colombia, publicó los resultados de un estudio sobre la supervivencia empresarial en el que evidencia cómo el $60 \%$ de las empresas en Colombia quiebran antes de cumplir cinco años, de las cuales el $98 \%$ son microempresas. De hecho, en el primer año tienden a desaparecer entre el $20 \%$ y el $30 \%$ de ellas. Estadísticamente se comprobó que de las 88406 empresas que se registraron en la Cámara de Comercio de Bogotá, en el 2017 cerrarán, aproximadamente, 22 100, y en el 2022, finalizados los primeros cinco años, apenas 35362 de aquellas seguirían activas en el mercado (Confecámaras, 2017).

El estudio de Confecámaras determina que existe correlación directa entre el tamaño del emprendimiento y su posibilidad de supervivencia: entre más grande sea el emprendimiento -empresa grande - menor será la posibilidad de quiebra, en contraste con las empresas pequeñas que tendrán alta probabilidad de fracaso. Esto evidencia también cómo aquellas empresas que cuentan desde sus comienzos con varios canales de distribución muestran mayores probabilidades de sobrevivir en el mercado colombiano. En la muestra poblacional estudiada en aquella investigación Confecámaras (2017) sugiere cuatro claves para que una empresa supere los primeros cinco años de vida: el servicio posventa, la innovación, el talento humano y las alianzas con proveedores.

Con relación al objeto de estudio de este trabajo y de forma directa con la región específica en la que se desarrolló, es decir, Aburrá Sur, la presidenta de la CCAS, Lillyam Mesa Arango, en el 2016 manifestó que el $96 \%$ de las empresas nuevas en Aburrá Sur son microempresas, y solo tres de cada diez sobreviven los primeros cinco años. Esto evidencia una tasa de fracaso de emprendimiento empresarial del $70 \%$. La Cámara de Comercio contaba para ese entonces con 48884 empresas registradas legalmente, del cual el 87,9 \% — 42 976 — son microempresas, el 2,9\% -4076- pequeñas, 1383 son medianas y apenas 445 empresas son grandes (Rojas, 2016).

Es importante resaltar que la presidenta de la CCAS, mediante esta entrevista, manifiesta la baja industrialización en estos municipios y cómo con seguridad tiende a bajar en razón a las condiciones de costo del terreno para establecer sus centros de operaciones. Además, Mesa (como se cita en Rojas, 2016) señaló: «Por eso la innovación no es un asunto instrumental, no solo es tener la tecnología o el experto, sino desarrollar mejores procesos productivos y formas de venta». Esto indica que de 7000 sociedades, apenas 527 están exportando, ni siquiera alcanzan a ser el $10 \%$, y casi la mitad de esas ventas en exportación recaen solo sobre dos empresas; expresa también la falta de internacionalización de las empresas y el fortalecimiento de la innovación y la promoción comercial para que las empresas abran nuevos mercados.

Según el Informe Diagnóstico Económico Vigencia 2017 de la Cámara de Comercio Aburrá Sur (CCAS, 2017), en el primer semestre - marzo y mayo — se realizó una investigación con el $37 \%$ de empresas pyme en el sector industrial, el $31 \%$ en comercio y el $32 \%$ en el sector servicios de la región en La Gran Encuesta pyme-Lectura Regional, 2018-II (ANIF, 2019); los tres macrosectores reportaron un descenso en el volumen de sus ventas en un $42 \%$.

El sector industrial atribuye el deterioro como principal problema -en un $44 \%$ - a la falta de demanda, al comercio -25\%- y a los servicios-34 \%—; tal vez la falta de promoción de ventas de sus productos/servicios es baja y no despiertan la suficiente demanda (Gupta y Cooper, 1992; Kopalle y Mela, 1999; Smith y Sinha, 2000). Por tal razón, esta investigación pretende revelar la actualidad del Marketing digital y el uso de herramientas de tecnologías de la información y la 
comunicación (TIC) en 13 empresas pymes inscritas a la CCAS de Antioquia, Colombia, y así reflexionar sobre el beneficio de la aplicación del Marketing digital para las pymes que contribuye a diferentes factores, como, por ejemplo, la disminución del fracaso del emprendimiento empresarial, el aumento de visibilización de las pymes para abarcar más mercado, aumentar las ventas $y$, finalmente, mejorar la administración de las redes sociales corporativas en función del Marketing digital.

\section{Metodología}

\subsection{Variables}

En la presente investigación se indagó sobre aspectos relevantes en la caracterización de la población, lo cual permitió encontrar resultados concluyentes, como, por ejemplo, la duración de la empresa en el mercado, la estructura organizacional, la planeación estratégica y la profesionalización del talento humano de la compañía. De igual manera, se realizaron preguntas referentes al conocimiento frente al Marketing digital, la presencia on-line del negocio, la percepción frente al Marketing digital, el e-commerce, la necesidad de planeación e implementación del Marketing digital en el negocio, así como la medición y la evaluación del Marketing digital mediante los indicadores clave de desempeño - KPI, por su siglas en inglés para key performance indicators- (Diez, Pérez, Pérez y Montes, 2012; Luu, Kim y Huynh, 2008).

\subsection{Participantes}

Se seleccionaron por conveniencia 13 empresas pymes inscritas en la Cámara de Comercio Aburrá Sur (CCAS) de diferentes sectores económicos, encuestadas de forma aleatoria por medio de una base de datos suministrada por la misma entidad; de estas, el 7,7 \% pertenece al sector agropecuario, el $30,8 \%$ al sector industrial, el 15,4 \% al comercial, el $23,1 \%$ a servicios y el $23,1 \%$ al sector tecnológico. Estas empresas se ubican, geográficamente, en alguno de los cinco municipios al sur del Área Metropolitana de Antioquia: Sabaneta, Envigado, Itagüí, La Estrella y Caldas -Antioquia-.

\subsection{Instrumentos de medición y técnicas}

El instrumento de medida lo desarrolló la plataforma de Google Formularios, y se envió a los correos electrónicos de los representantes legales de las empresas como fuentes primarias de información. El cuestionario se estructuró con 36 variables divididas en dos segmentos. El primer segmento se compone de la caracterización de la muestra con diez variables, y el segundo segmento, sobre Marketing digital, con las 26 variables restantes. Se realizaron preguntas abiertas, dicotómicas, politómicas, de selección múltiple con única respuesta y escala de Likert con cinco opciones de respuesta, concluyendo como positivas las primeras dos, en las categorías de frecuencia, acuerdo a desacuerdo y nivel de importancia.

\subsection{Procedimientos}

Se seleccionó de forma aleatoria a los participantes de una base de datos suministrada por la CCAS. Dada la delicadeza del manejo de la información en razón a la protección de tratamiento de datos personales, el instrumento se les envió vía e-mail. Este procedimiento se apoyó en la táctica de telemercadeo, la cual sirvió para resolver el cuestionario en las 13 empresas pymes de diferentes sectores económicos. El trabajo de campo se ejecutó entre el 20 de octubre y el 26 de noviembre del 2018.

\subsection{Análisis estadístico}

El proceso estadístico se fundamentó en la metodología del análisis multivariado para la presentación del informe. Inicialmente, se calcularon 
frecuencias $-\mathrm{n}-$, medidas de tendencia central media-M- y dispersión — desviación típica DT—, el coeficiente de correlación - $\mathrm{r}-\mathrm{y}$ la reproducción de la variabilidad original de cada ítem. Acto seguido, se realizó el análisis de confiabilidad alpha de Cronbach con el fin de validar que el instrumento tenga consistencia interna entre los ítems y sus escalas de medición según los criterios de fiabilidad de George y Mallery (2003). Por consiguiente, se desarrolló un análisis factorial exploratorio (AFE) con aplicación del software SPSS V25 $5^{\oplus}$ mediante el cual se identificaron los factores de mayor correlación y agrupación entre variables.

Finalmente, se presentan los análisis estadísticos del Chi cuadrado que se utilizaron para corroborar la relación de variables dependientes y se proyectó el análisis de Box-Plot —box and whisker- (Walpole, Myers, Ye y Myers, 2012) con el fin de verificar la diferencia de las variables y su dispersión según los rangos intercuartílicos.

\section{Resultados}

\subsection{Generales}

Dados los resultados expuestos en la figura 4, se deduce mediante la caracterización de la población encuestada que solo el $15,4 \%$ de las empresas tienen menos de diez años en actividad, y el 30,8 \% de la

población investigada son empresas industriales, lo que ubica a este sector con mayor antigüedad en el mercado del total de las empresas que resolvieron el cuestionario.

Figura 4. Caracterización de la población - Tipo de producto o servicio / Tiempo de funcionamiento / Número de empleados

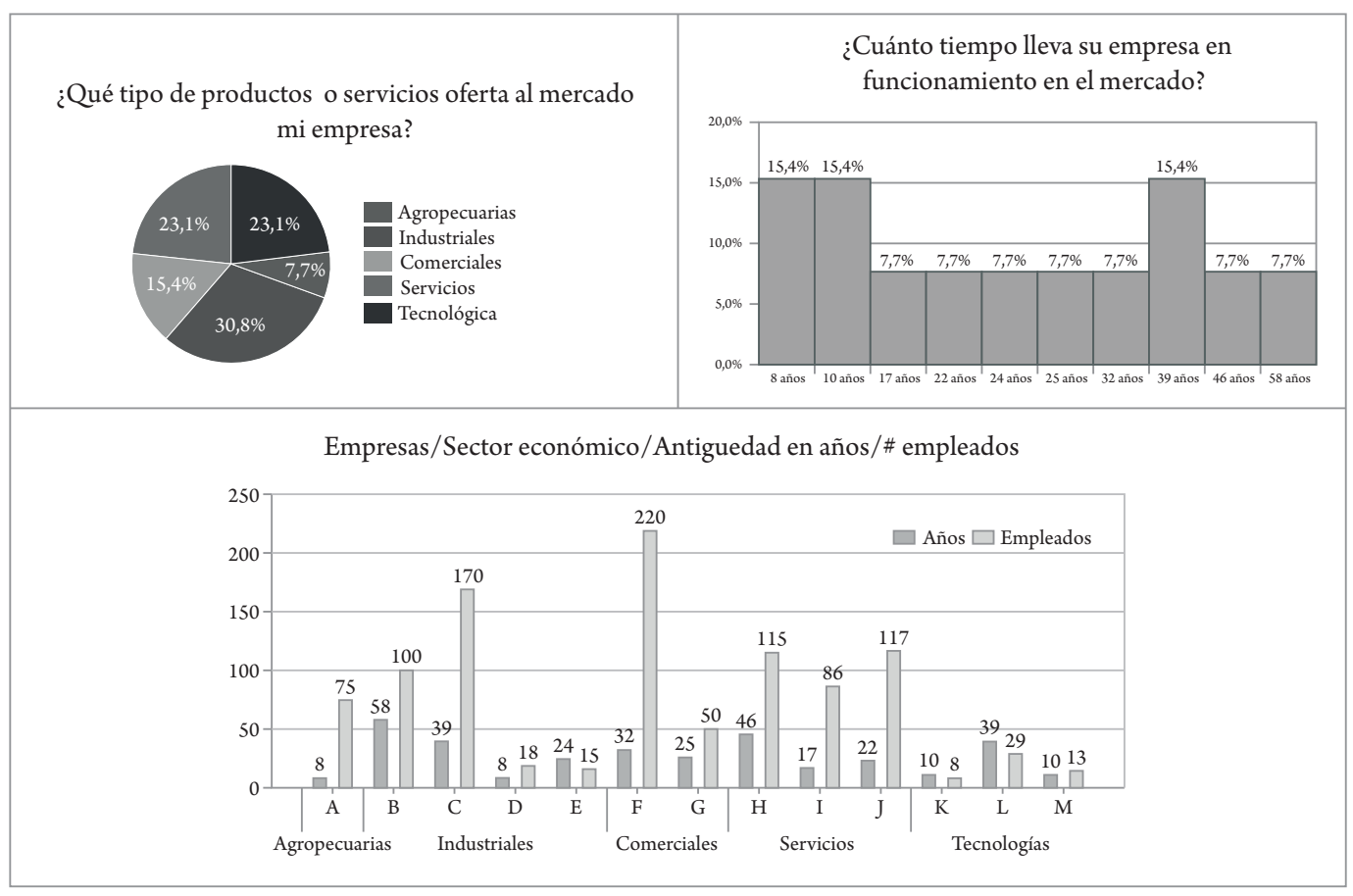

Fuente. Elaboración propia. 
El $100 \%$ de las empresas encuestadas cuentan con un organigrama en su empresa, gracias a su importancia, la cual se percibe en la mayoría de los empresarios, pues el $77 \%$ cree que tener un organigrama es determinante para ser competitivo.

El 84,6 \% de los encuestados confiesan contar con áreas fusionadas dentro de su compañía, como lo es el área comercial y de mercadeo, en primer lugar, con una tasa de frecuencia del $54 \%$, en contraste con el 69,3\% de empresas convencidas de que si tienen un profesional en cada área serán mucho más competitivas, pues el $77 \%$ de los encuestados asegura tener el personal idóneo, formado profesionalmente y capacitado para cada área de su empresa. En este hallazgo se evidencia la importancia del primer objetivo de investigación y su relación directa, suponiendo que las empresas que tengan fusionadas en gran porcentaje el área de mercadeo con otras áreas obtendrán menos especialidad en el Marketing y sus actividades en términos digitales; así como tendrán menor dedicación al Marketing digital en la medida en que se cuente con menos personas especializadas sobre este tema en concreto.

Figura 5. Existencia de organigrama / Áreas de la empresa

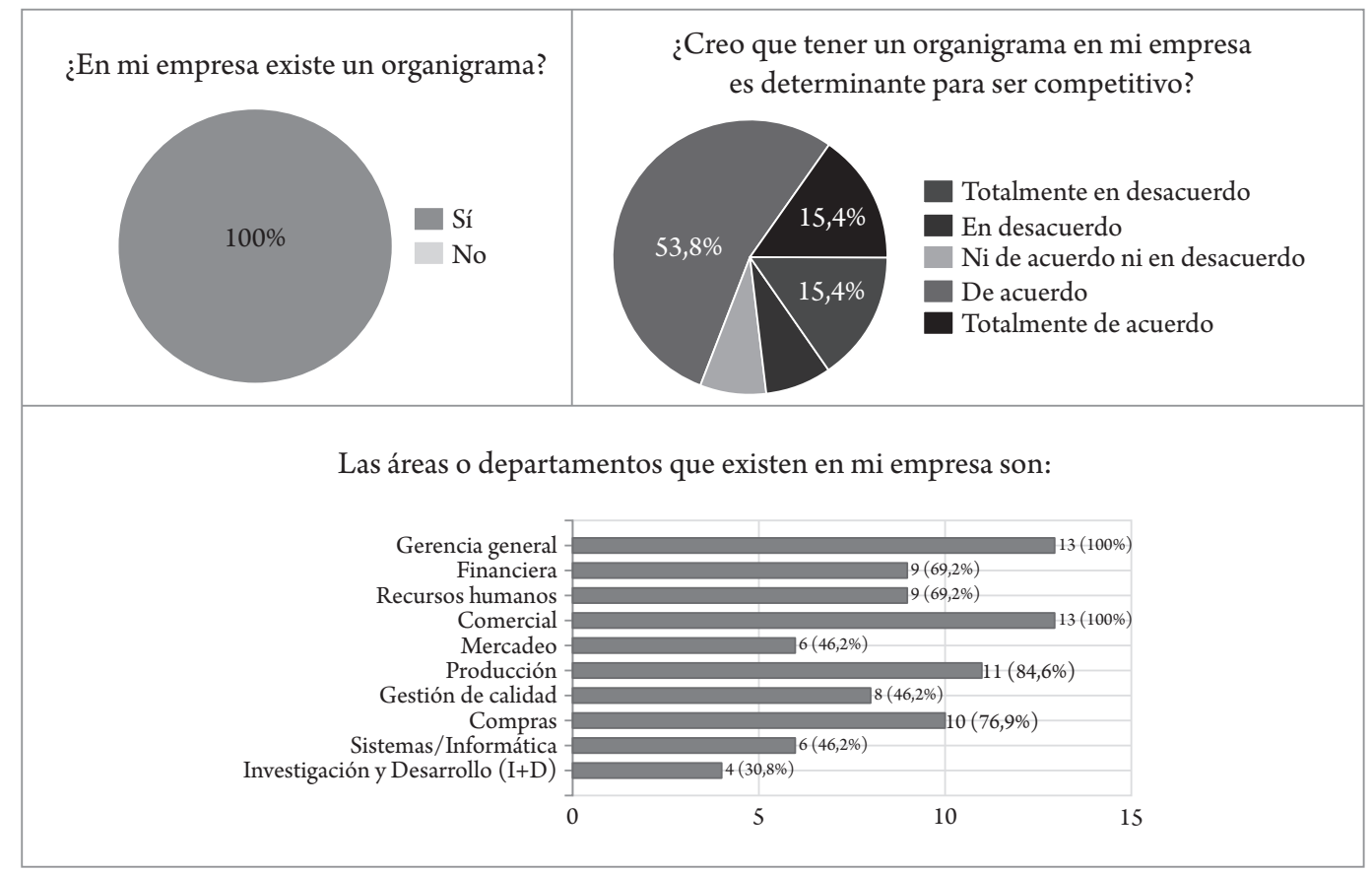

Fuente. Elaboración propia.

Las áreas o los departamentos que existen en estas empresas son, con mayor frecuencia, la gerencia y el área comercial, con un $100 \%$; en segundo lugar, producción, con un $84,6 \%$; tercero, compras, con un $76,9 \%$; cuarto, el área financiera y de recursos humanos, con el 69,2\%; en la quinta posición se encuentra gestión de calidad, con el 61,5\%; en la sexta las áreas de sistemas/informática y mercadeo, con un 46,2 \%, y en el último lugar, con gran asombro, el área de investigación y desarrollo (I+D) con apenas el 30,8 \%. La relación directa con el problema de investigación es imperante en este hallazgo, pues no contar con un departamento definido y solo con dedicación completa al Marketing lleva a que las empresas no obtengan resultados óptimos en función de la comercialización. 
Figura 6. Calidad del personal / fusión de áreas

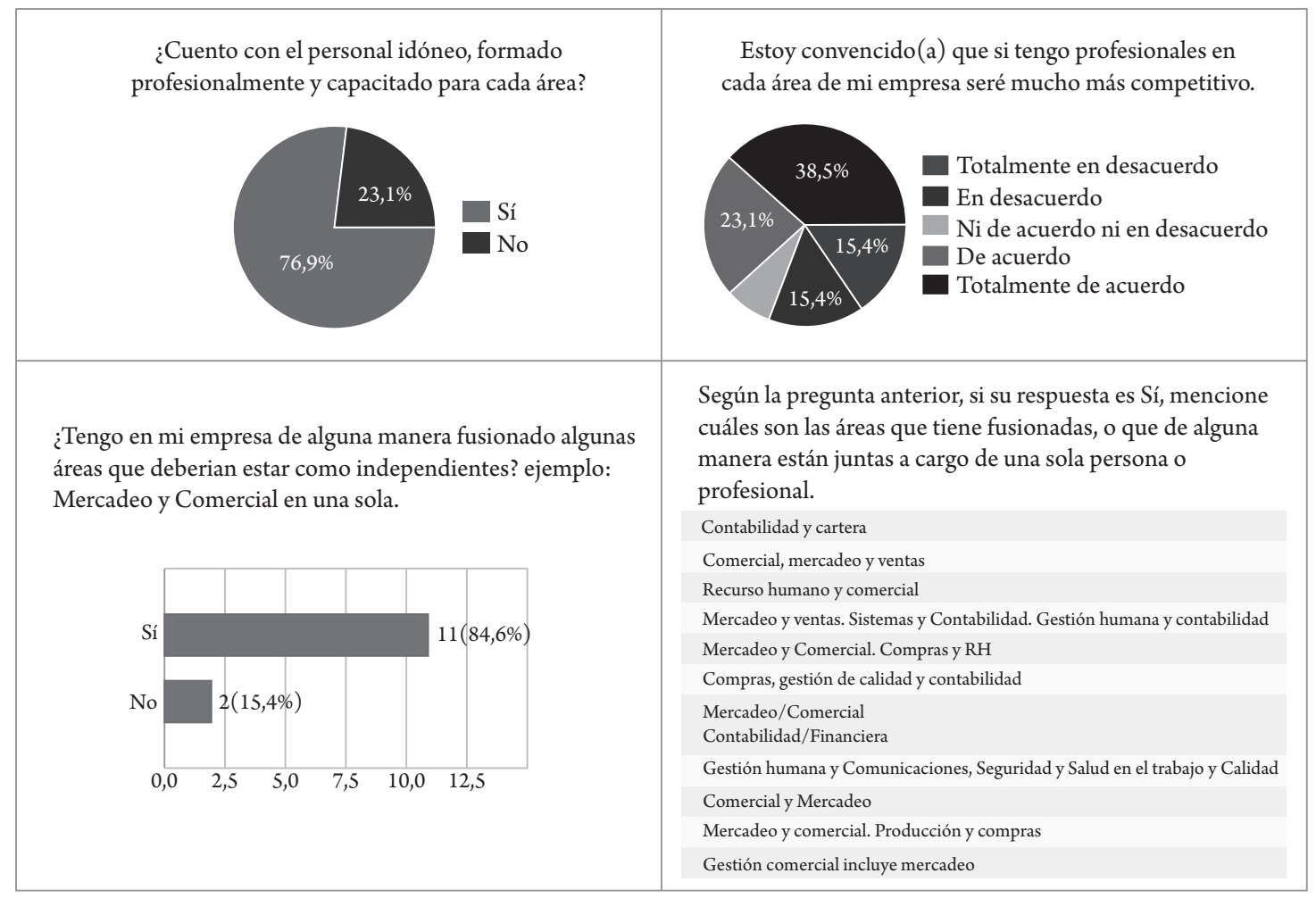

Fuente. Elaboración propia.

Se detecta una alta necesidad de este trabajo investigativo, de modo que la mayoría no cuentan con este departamento $-\mathrm{I}+\mathrm{D}+\mathrm{i}-\mathrm{y}$ no se da relevancia al Marketing digital como variable del Marketing mix en la promoción de la marca y los productos, si se considera que la mayoría de las empresas encuestadas no tienen este departamento en su estructura organizacional.

En los resultados descriptivos generales se puede observar los gráficos estadísticos de las respuestas del segundo segmento de preguntas concernientes al tema de este trabajo. Como hallazgo principal se detectó que el 92,3 \% de las empresas encuestadas sabe qué es el Marketing digital y para qué sirve, reconociendo que no lo consideran un gasto para su empresa en un $76,9 \%$-mayoría—, sino una inversión; aunque el 53,8 \% considera costoso invertir en Marketing digital. Los empresarios encuestados prefieren contratar una persona que se encargue del Marketing digital en vez de tercerizarlo con otra empresa en un $46,2 \%$, la misma cantidad — 46,2 \%- ha pagado en el último año por estos servicios, y un $92,3 \%$ confirma que necesitan ayuda o encargar a una persona en la empresa para que desarrolle actividades de Marketing digital.

El $77 \%$ de las empresas consideran el sitio web una herramienta muy valiosa para vender sus productos $y$ servicios. Esta misma cantidad está convencida de que pueden vender sus productos y servicios por medio del sitio web; además, el 92,3 \% cree que por este mismo medio - sitio web - pueden generar bases de datos interesantes para su empresa. Sin embargo, en contraste encontramos que el $84 \%$ no implementa el comercio electrónico -e-commerce- para vender sus productos/servicios, aunque saben que el comercio electrónico presenta una alta tendencia como parte integral del Marketing digital enmarcado en el crecimiento del mercado para las empresas (Hudák, Kianičková y Madleňák, 2017; Kannan y Li, 2017). Esta cifra puede ser mayor si se considera que ninguno de los encuestados implementa su sitio web 
como plataforma e-commerce, pues lo usan como exhibición de sus productos y servicios sin tener sus precios publicados ni formas claras de venta de productos o pago on-line.

El 84,6 \% de los encuestados estiman que las redes sociales son un complemento para hacer visible su empresa y posicionar sus productos; el 53,8 \% de las publicaciones en sus redes sociales y sitio web lo hacen los mismos empresarios, el 23,1\% no hacen publicaciones y solo el $23,1 \%$ terceriza estas actividades. Sin embargo, el 23,1 \% tiene políticas establecidas para los planes de publicación y comunicación en su sitio web y redes sociales, mientras que el $38,5 \%$ revela que no lo han realizado. El $84,7 \%$ de los encuestados cree que desarrollar Marketing de contenidos ayuda a posicionar su marca $\mathrm{y}$ atrae a su público objetivo.

Por otro lado, el 61,5\% manifiesta no tener un plan claro con fechas de publicaciones, ejecuciones, responsables de publicaciones y métricas, frente al $38,5 \%$ restante. En contraste, el 30,8 \% — negativode empresas miden el alcance e impacto de las publicaciones en las redes sociales, aunque el 92,3\% considera importante conocer el crecimiento de la marca, los productos y los servicios en redes sociales, así como todas las publicaciones que realizan.

El 53,9 \% de los resultados encontrados frente a la implementación de herramientas TIC orientadas a facilitar los ejercicios digitales son positivos; del mismo modo, son positivos los resultados frente a la importancia que le dan a implementar multiplataformas digitales para sus empresas, en vista de que son necesarias para llegar a su público objetivo, lo que se evidencia en un $77 \%$. Solo el $15,4 \%$ ha considerado implementar un aplicativo móvil app - en su empresa; la mayoría de los encuestados — 61,6 \% — no envían información a sus públicos a través de mensajes de texto a sus celulares, toda vez que el 46,2 \% envía información relevante para su público objetivo como promoción de sus productos y servicios.

\subsection{Descriptivos, consistencia interna del instrumento y AFE}

Los resultados obtenidos en la muestra se describen en la tabla 4, identificados con 16 ítems del instrumento; la confiabilidad del instrumento arrojó un alfa de Cronbach de 0,603 , si se elimina el ítem 2 y 3 con consistencia de tipo cuestionable. Si se eliminan los ítems 5, 7, 12 y 13 sube la consistencia a aceptable - $\alpha$ = 0,798-; no obstante, si además se elimina el ítem 23 y se aplica el criterio que propone Comrey (1985) de coeficientes mayores a 0,3 , aumenta la consistencia a buena $-\alpha=0,821-$ con 16 ítems, según el criterio de George y Mallery (2003).

El coeficiente de correlación de Pearson señala que el ítem 18 es el de mayor correlación - 0,757—; las correlaciones oscilan entre 0,095 y 0,76 , con una correlación promedio de 0,46 ; el modelo es capaz de reproducir el $94 \%$ de su variabilidad original. Por otro lado, los ítems peor explicados son el 26 y 17 con una reproducción de su variabilidad original del $63,3 \%$ y el $79 \%$, respectivamente. Si se tiene en cuenta que todos los parámetros son mayores que 0,6, todos son importantes para explicar el problema y generar factores. 
Tabla 4. Estadísticos descriptivos y análisis de consistencia interna del instrumento de medida

\begin{tabular}{|c|c|c|c|c|c|c|}
\hline Ítem & $\mathbf{M}$ & DT & $\neq \mathbf{M}$ & Ext & $\mathbf{r}$ & $\boldsymbol{\alpha}$ \\
\hline $\begin{array}{l}\text { I15-Tengo un plan claro con fechas de publicaciones, ejecuciones, responsables, } \\
\text { métricas }\end{array}$ & 2,77 & 1,363 & 2,769 & 0,918 & 0,590 & 0,799 \\
\hline $\begin{array}{l}\text { I16-Mido el alcance e impacto de las publicaciones en las redes sociales de mi } \\
\text { empresa }\end{array}$ & 2,38 & 1,502 & 2,385 & 0,940 & 0,635 & 0,795 \\
\hline $\begin{array}{l}\text { I17-Tengo políticas establecidas y avaladas por los órganos de decisión para los } \\
\text { planes de publicaciones y comunicación en mi sitio web y/o redes sociales }\end{array}$ & 2,31 & 1,251 & 2,308 & 0,790 & 0,584 & 0,800 \\
\hline $\begin{array}{l}\text { I18-Considero que las redes sociales son un complemento para hacer visible mi } \\
\text { empresa y posicionar mis productos }\end{array}$ & 4,54 & 0,776 & 4,538 & 0,838 & 0,757 & 0,798 \\
\hline $\begin{array}{l}\text { I19-Considero que debo conocer el crecimiento de mi marca, productos/ } \\
\text { servicios en redes sociales y todas las publicaciones que realice }\end{array}$ & 4,54 & 0,660 & 4,538 & 0,930 & 0,692 & 0,804 \\
\hline $\begin{array}{l}\text { I20-Debo tener ayuda o una persona encargada en mi empresa para que } \\
\text { desarrolle actividades de Marketing digital }\end{array}$ & 4,54 & 0,660 & 4,538 & 0,930 & 0,692 & 0,804 \\
\hline I21-Estoy convencido/a de que el Marketing digital es un gasto para mi empresa & 3,54 & 1,198 & 3,538 & 842 & 0,095 & 0,833 \\
\hline $\begin{array}{l}\text { I24-Implemento herramientas TIC —-tecnologías de la información y } \\
\text { comunicación-para facilitar mis ejercicios digitales de mi empresa }\end{array}$ & 3,62 & 1,044 & 3,615 & ,930 & 0,149 & 0,827 \\
\hline $\begin{array}{l}\text { I25-Implementar multiplataformas digitales para mi empresa es necesario para } \\
\text { llegar a mi público objetivo de manera más sencilla y oportuna }\end{array}$ & 4,00 & 0,913 & 4,000 & 0,876 & 0,336 & 0,816 \\
\hline $\begin{array}{l}\text { I26-Envío información relevante para el público objetivo de mi empresa a } \\
\text { través del correo electrónico - e-mail- }\end{array}$ & 3,62 & 0,961 & 3,615 & 0,633 & 0,524 & 0,806 \\
\hline $\begin{array}{l}\text { I27-Envío información relevante para el público objetivo de mi empresa a } \\
\text { través de mensajes de texto - SMS - a sus celulares }\end{array}$ & 2,69 & 1,653 & 2,692 & 0,815 & 0,439 & 0,814 \\
\hline $\begin{array}{l}\text { I28-He considerado implementar un aplicativo móvil —app — en mi empresa } \\
\text { para mi público objetivo }\end{array}$ & 2,23 & 1,363 & 2,231 & 0,841 & 0,363 & 0,817 \\
\hline $\begin{array}{l}\text { I29-Estoy convencido que puedo vender mis productos/servicios por medio } \\
\text { de sitio web }\end{array}$ & 4,08 & 1,115 & 4,077 & 0,882 & 0,539 & 0,804 \\
\hline $\begin{array}{l}\text { I30-Implemento en mi empresa el comercio electrónico —e-commerce- }- \text { para } \\
\text { vender más mis productos/servicios }\end{array}$ & 2,08 & 1,320 & 2,077 & 0,839 & 0,150 & 0,832 \\
\hline $\begin{array}{l}\text { I31-Creo que desarrollar content Marketing - Marketing de contenidos- } \\
\text { ayuda a posicionar mi marca digitalmente y atraer a mi público objetivo }\end{array}$ & 4,23 & 0,725 & 4,231 & 0,867 & 0,608 & 0,806 \\
\hline $\begin{array}{l}\text { I33- Estoy interesado en pertenecer a una red de pymes para comunicaciones, } \\
\text { publicidad y Marketing digital que convenga a mi empresa }\end{array}$ & 4,46 & 0,660 & 4,462 & 0,854 & 0,278 & 0,819 \\
\hline$\%$ de varianza explicada $=85,79 \%$ & 3,85 & 0,555 & 3,476 & 0,858 & 0,464 & 0,821 \\
\hline
\end{tabular}

Fuente. Elaboración propia.

El valor de la media total es de 3,85, en un rango de 1 a 5 , con el coeficiente más bajo en el ítem $30-\mathrm{M}$ $=2,08 ; \mathrm{DT}=1,32-\mathrm{y}$ el máximo en los ítems 18,19 y $20-\mathrm{M}=4,54 ; \mathrm{DT}=0,776-,-\mathrm{M}=4,54 ; \mathrm{DT}=$ $0,66-\mathrm{y}-\mathrm{M}=4,54 ; \mathrm{DT}=0,66-$, respectivamente, con mejor desviación en el ítem 19 y 20. La varianza con mayor desviación es el ítem $27-1,653-$ diferenciado de los demás datos. Como se muestra en la tabla 4, la consistencia interna del instrumento es alta y positiva en 13 de los 16 ítems al tener la mejor consistencia en el ítem $21-\alpha=0,833-$.
Por otra parte, con el objetivo de realizar un AFE con el fin de lograr la validación del instrumento, en la tabla 5 se observan los descriptivos de cada uno de los ítems; por tanto, se extrajeron cinco factores bajo el método de «componentes principales» con técnica multivariante y método factorial bajo el criterio de Kaiser (Guisande, Vaamonde y Barreiro, 2011), con el propósito de reducir el conjunto de ítems del instrumento. Aunque la prueba KMO y la prueba de Bartlett resultaron una matriz no cierta positiva, se entiende que se ha explicado el $85,79 \%$ de la varianza total de los datos. El factor ACMD tiende a explicar 
mejor el problema en un 37,6 \%, contrario al factor TIC que menos tiende a explicarlo, con el 7,99\%.

En los factores extraídos se evidencian coeficientes excelentes en los factores ACMD $-\alpha=0,905-y$
GP — $\alpha=0,92-$, pero con coeficientes pobres en SC $-\alpha=0,53-y$ GSMS $-\alpha=0,54-$. En el factor TIC solo existe un ítem del instrumento, por tanto, no se tiene la representatividad suficiente para asociarlo a un grupo específico.

Tabla 5. Estadísticos descriptivos y análisis de consistencia por factor

\begin{tabular}{|l|c|c|c|c|}
\hline \multicolumn{1}{|c|}{ Factor } & M & DT & As & $\boldsymbol{a}$ \\
\hline ACMD & 4,62 & 0,650 & $-1,576$ & 0,905 \\
\hline GP & 2,77 & 1,301 & 0,233 & 0,923 \\
\hline SC & 2,31 & 1,251 & 0,216 & 0,529 \\
\hline GSMS & 3,31 & 1,251 & $-0,086$ & 0,536 \\
\hline TIC & 3,62 & 1,044 & $-0,101$ & - \\
\hline
\end{tabular}

ACMD: actividades para el crecimiento de la empresa apoyadas en Marketing digital; GP: gestión de publicaciones; SC: soluciones comerciales; GSMS: gastos y mensajes de texto SMS; TIC: tecnologías de la información y la comunicación.

Fuente. Elaboración propia con base en datos SPSS V25 ${ }^{\circledR}$

El factor mejor implementado es el $A C M D-M=$ $4,62, D T=0,650-$, y el peor es el factor $S C-M=$ $2,31, D T=1,251-$ En cuanto a los correlaciones, se encontraron correlaciones fuertes entre los ítems 15 y $16-0,901$ - y débiles entre los ítems 30 y 25 - 0,415-. Del mismo modo, entre los factores extraídos se halló una correlación fuerte entre GP y TIC del 0,297 —entre los coeficientes bajos-y la correlación más débil entre el factor ACMD y SC $-0,047$.

\subsection{Dependencia entre variables-prueba de chi cuadrado - $\chi^{2}-$}

Estadísticamente, se presentan a continuación los resultados contrastados. Se hallaron variables dependientes con el $95 \%$ de nivel de confianza.

Los resultados se validaron mediante la estadística chi cuadrada, en adelante representada como $\chi^{2}$ (Briones, 2003), de tal forma que las variables que se representan en la tabla 6 son variables dependientes $\mathrm{Ha}$ en un alto grado con dos niveles de confianza del $99 \%$ y el $95 \%$. Se tiene en cuenta la relación de las variables de dependencia $(\mathrm{Ha})$ o variables de independencia como hipótesis nula ( $\mathrm{H} 0)$.

Tabla 6. Prueba del chi cuadrado entre variables dependientes

\begin{tabular}{|l|l|c|c|}
\hline \multicolumn{1}{|c|}{ Variable A } & \multicolumn{1}{|c|}{ Variable B } & $\begin{array}{c}\text { Nivel de } \\
\text { confianza }\end{array}$ & $\begin{array}{c}\mathbf{X}^{2} \text { chi } \\
\text { cuadrado }\end{array}$ \\
\hline $\begin{array}{l}\text { Sé qué es el Marketing digital y para } \\
\text { qué sirve. }\end{array}$ & $\begin{array}{l}\text { Las publicaciones en las redes sociales y sitio web las } \\
\text { hago a través de... }\end{array}$ & $99 \%$ & 0,007 \\
\hline $\begin{array}{l}\text { Mido el alcance e impacto de las } \\
\text { publicaciones en las redes sociales de } \\
\text { mi empresa. }\end{array}$ & $\begin{array}{l}\text { Tengo un plan claro con fechas de publicaciones, } \\
\text { ejecuciones, responsables y métricas. }\end{array}$ & $95 \%$ & 0,018 \\
\hline $\begin{array}{l}\text { iQué tipo de productos o servicios } \\
\text { oferta al mercado mi empresa? }\end{array}$ & $\begin{array}{l}\text { Estoy convencido de que por medio de mi sitio web } \\
\text { puedo generar una base de datos interesante para mi } \\
\text { empresa. }\end{array}$ & $95 \%$ & 0,049 \\
\hline
\end{tabular}

Fuente. Elaboración propia con base en datos SPSS V25 ${ }^{\circledR}$. 


\subsection{Variabilidad y dispersión de datos}

Finalmente, se presentan los gráficos de Box-Plot. Estos gráficos determinan la variabilidad de los datos y sus medianas en los resultados, analizando, a su vez, los rangos intercuartílicos (RIC) (Walpole et al., 2012).

En la figura 5 se puede determinar la mayor dispersión (Walpole, et al., 2012) en las variables «tipo de empresas», en las que se encuentran, puntualmente, los sectores industrial, servicios y tecnología. Además, se observa que el $38 \%$ de las medianas desde los 22 años hasta los 40 se encuentran en el mercado de los sectores comercial, industrial y servicios. Aquellas empresas que pertenecen al sector agropecuario y comercial presentan menor dispersión de los datos; el rango intercuartílico (RIC) de los cuatro gráficos oscila entre los ocho años de existencia en el mercado hasta los 58 años, es decir, la variabilidad central de los años de existencia en el mercado es bastante alta dado que son 50 años de variabilidad en existencia de las pymes.

Figura 7. Box and whisker plot-tiempo en el mercado, organigrama. Tipo de productos que oferta el mercado y otras variables

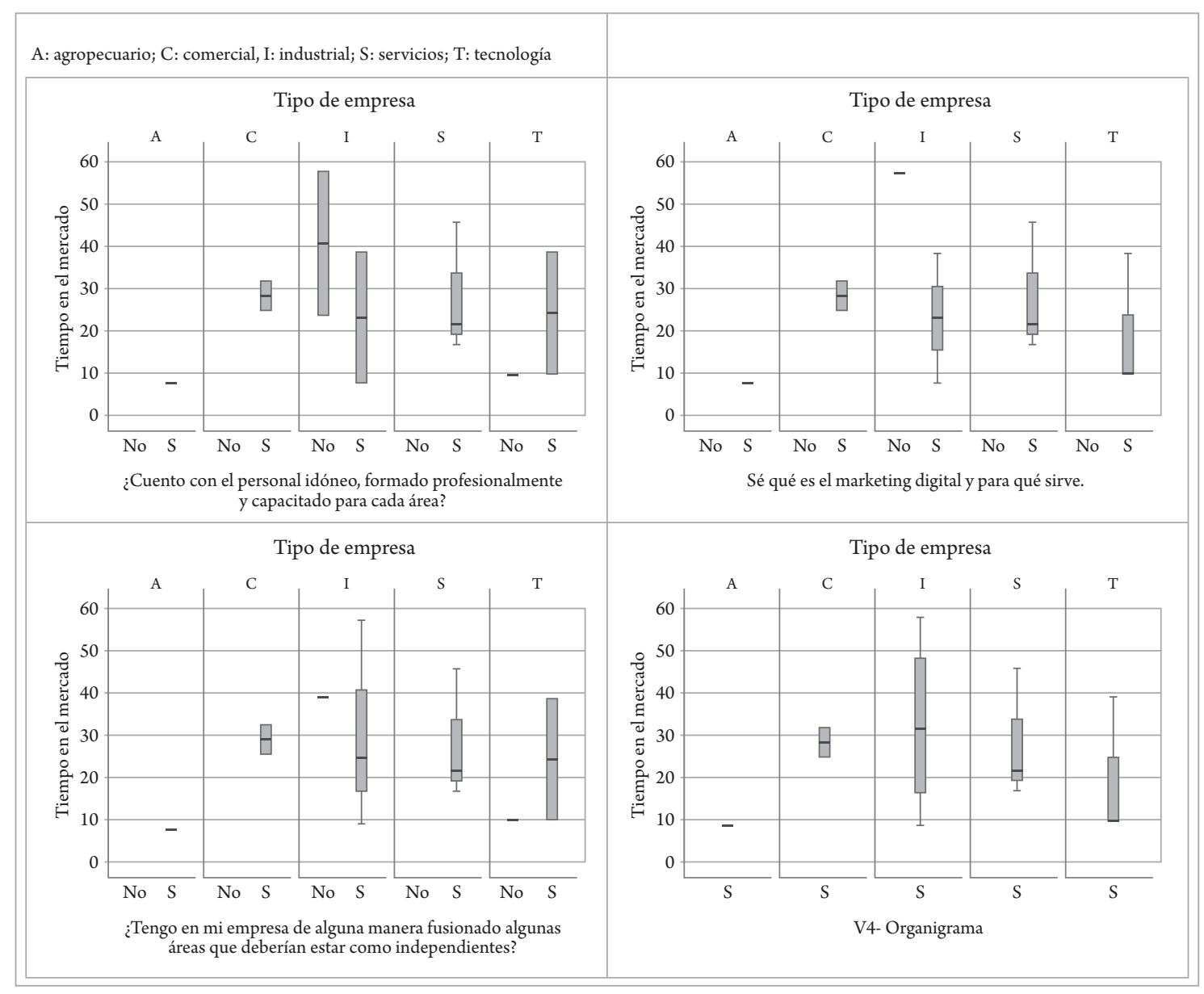

Fuente. Elaboración propia con base en datos SPSS V25 .

Las empresas que pertenecen al sector comercial son aquellas que menor variabilidad presentan en los datos, dado que el segundo y tercer RIC están ubicados entre los 25 y los 33 años, es decir, aproximadamente una elongación de ocho años. 


\section{Discusión}

$F^{\prime}$ rente a los hallazgos expuestos es necesario tener - presente que son solo 13 empresas a las que se les realizó el trabajo de campo, y sus resultados no generalizan el comportamiento de los sectores económicos ni de toda la subregión antioqueña. No obstante, este estudio evidencia que, si las empresas no tienen un departamento de investigación y desarrollo, disminuye su capacidad de innovación, lo que lleva a que se opte por mecanismos de promoción en Marketing digital, tal como lo indica el problema de investigación que revela la actualidad del Marketing digital en estas pymes.

Fue posible corroborar la validez de este trabajo investigativo en el que existe coherencia directa con los objetivos planteados inicialmente yla fundamentación teórica actualizada frente al Marketing digital y el uso de herramientas TIC, en cuanto determinantes para aplicar en las empresas que buscan ser competitivas en Colombia y asegurar así su permanencia en el mercado (Prada, 2016).

Otros proyectos investigativos referentes a la temática de este trabajo coinciden en la pertinencia de la aplicación del Marketing digital como apoyo a la visibilización y venta de los productos y servicios de las empresas. Arredondo (2017) concluye su tesis con que las empresas deben mantenerse a la vanguardia de la tecnología y la adaptación al cambio, aplicando el Marketing digital, ya que traerá beneficios apostándole a la innovación en sus empresas, y lo califica como una «herramienta sumamente importante que puede impulsar al éxito a cualquier tipo de empresa» (Arredondo, 2017).

Otros estudios determinan que «el Marketing digital supone un avance crucial en los negocios internacionales especialmente de las pymes» (Hernández, 2013). Así mismo, la gestión de este ejercicio en Colombia todavía se encuentra en sus primeras etapas y pretende su maduración en este tipo de actividades y tácticas. El autor sugiere la implementación del Marketing digital como gran herramienta en su internacionalización y posicionamiento. Del mismo modo, Prada (2016) conversa con la propuesta que se expuso, en el sentido de que las empresas deben identificar y elegir las herramientas TIC que se ajusten a sus propias necesidades, además de que se debe contar con el personal idóneo con conocimientos específicos para gestionarlas y sacar sus respectivos indicadores de gestión (Diez et al., 2012).

Estas investigaciones, sumadas al estudio de Londoño et al. (2018), además de los hallazgos presentados y la fundamentación teórica de este trabajo en el marco empírico, argumentan que la ausencia de estrategias en Marketing digital se suma al sinnúmero de posibilidades de fracaso empresarial prematuro en la actualidad competitiva del entorno de las empresas, sobre todo, en las colombianas. 


\section{Conclusiones}

A raíz de la revisión literaria se identifican algunos componentes del Marketing digital y su importancia en las pymes. Además, se puede destacar que implementar el Marketing digital, como lo presenta este trabajo, es determinante para el sector empresarial de Aburrá Sur, ya que aporta a la innovación y la oferta de los productos a nivel internacional en términos de internacionalización y promoción comercial en nuevos mercados, debido a la importancia del buen manejo y de las buenas prácticas en el Marketing digital que se le otorgue desde su propio plan de negocios (Diez, 2006). Este aspecto fundamenta el panorama de la subregión Aburrá Sur y sustenta la lectura y las conclusiones de la presidenta de la CCAS.

En la caracterización de estas empresas se identificó que las pymes no creen en la importancia del departamento de investigación, desarrollo e innovación $(\mathrm{I}+\mathrm{D}+\mathrm{i})$ junto con el departamento de mercadeo, ya que se encuentran entre los últimos lugares en las áreas existentes en sus organigramas, a pesar de que son de alta importancia para una compañía en el mundo competitivo. Si se tiene en cuenta que, según la información revelada por la presidenta de la CCAS en su entrevista con el diario El Colombiano, uno de los aspectos de mayor preocupación es la innovación y la oferta de productos y servicios en nuevos mercados o su internacionalización, por eso se determina que estas áreas son decisivas y de alta preocupación en la subregión, pues se sabe que el Marketing digital como herramienta del comercio electrónico ha tenido rápido crecimiento en la economía mundial (Londoño et al., 2018).

Así mismo, aunque los empresarios tengan noción de la importancia del Marketing digital, no lo aplican cabalmente ni invierten en estas tácticas de forma adecuada como estrategias que apalanquen su negocio; además, lo consideran un gasto y no una inversión. No obstante, el $100 \%$ está dispuesto en invertir entre COP 500000 y COP 1000000 para recibir capacitación sobre el Marketing digital, a pesar de su actual implementación empírica. Los empresarios no aplican el Marketing digital con las debidas métricas y mediciones adecuadas. Del mismo modo, el sector comercial se comporta de forma homogénea al no existir baja variabilidad de los datos expresados, lo cual indica singularidad del comportamiento en este sector empresarial. Por su parte, los resultados fundamentan la teoría que se basa en que las empresas grandes son más competitivas y organizadas con respecto a los ámbitos del Marketing digital, así como queda demostrado que las empresas entre más pequeñas son más propensas al fracaso.

Finalmente, se concluye que este trabajo cumple con los objetivos propuestos, argumentados en los resultados descritos y validados estadísticamente, así como aporta a la comunidad científica para posteriores investigaciones. En este sentido, tal vez se requiera una muestra mayor en aspectos relacionados con la aplicación del Marketing digital de las empresas en otras subregiones del mercado colombiano, en las cuales se haga un estudio desde los factores expuestos en el presente trabajo, a fin de evaluar el Marketing digital en las empresas.

Este trabajo argumenta la recomendación para los empresarios de estructurar un departamento de mercadeo definido solo para sus actividades propias con funciones en el Marketing digital, promoviendo la utilización de métricas, mediciones y usos de herramientas TIC relacionados con la visibilización de la marca, el posicionamiento de sus productos a nivel internacional y el retorno a la inversión (ROI); de esta forma, defiende la importancia de los informes presentados a los directivos con el propósito de probar la pertinencia y la viabilidad de la inversión en 


\section{Marketing digital.}

\section{Referencias}

Adán, P.; Arancibia, R.; López, A.; Ramírez, J. L.; Sospedra, R.; Valladares, A. (2015). Bussines to social. Marketing digital para empresas y personas. Madrid: SC Libro.

Andrade, D. (2016). Estrategias de Marketing digital en la promoción de marca ciudad. Revista Escuela De Administración De Negocios, (80), 59-72. DOI: https://doi. org/10.21158/01208160.n80.2016.1457

ANIF (Asociación Nacional de Instituciones Financieras). (2019). La gran encuesta pyme. Recuperado de http://hdl. handle.net/11520/24065

Arredondo, J. C. (2017). Marketing digital: una solución estratégica para las microempresas (Tesis de especialización). Universidad Militar Nueva Granada, Bogotá, Colombia. Recuperado de http://hdl.handle.net/10654/16196

Axon Logística. (2012). ¿Qué es Marketing? Entrevista Phillip Kotler [Video]. Recuperado de https://www.youtube.com/ watch?v=TCpNzWdoO3Y

Briones, G. (2003). Métodos y técnicas de investigación para las ciencias sociales. México: Trillas.

CCAS (Cámara de Comercio Aburrá Sur). (2017). Diagnóstico económico vigencia 2017.

Comrey, A. (1985). Manual de análisis factorial. Madrid: Cátedra.

Confecámaras. (2017). Confecámaras presenta dos estudios en los que analiza los factores que explican el éxito y fracaso de las empresas en Colombia y las claves para su crecimiento extraordinario. Recuperado de https://bit.ly/2B5xNko

Diez, H. (2006). Espíritu emprendedor: reto permanente de la academia. Reflexiones sobre la experiencia del modelo de incubación de la universidad de Pamplona. Revista FACE Facultad de Ciencias Económicas y Empresariales, 2(2), 19-26. DOI: https://doi.org/10.24054/01204211.v2.n2.2006.1920

Diez, H.; Pérez, M.; Pérez, F. N.; Montes, M. (2012). Medición del desempeño y éxito en la dirección de proyectos: perspectiva del manager público. Revista Escuela de Administración de Negocios, (73), 60-79. DOI: https://doi.org/10.21158/01208160. n73.2012.586

George, D.; Mallery, P. (2003). SPSS/PC step by step: a simple guide and reference. Belmont, CA. EE. UU.: Wadsworth Publishing Co.

Gupta, S.; Cooper, L. (1992). The discounting of discounts and promotion thresholds. Journal of Consumer Research, 19(3), 401-411. DOI: https://doi.org/10.1086/209310

Guisande, C.; Vaamonde, A.; Barreiro, A. (2011). Tratamiento de datos con R, Statistica y SPSS. España: Ediciones Díaz de Santos.
Hernández, C. D., (2013). Importancia del Marketing digital para las pymes colombianas orientadas a los negocios internacionales (Tesis de maestría). Universidad Militar Nueva Granada. Bogotá, Colombia. Recuperado de http://hdl.handle. net/10654/11579

Hudák, M.; Kianičková, E.; Madleňák, R. (2017). The importance of e-mail Marketing in e-commerce. Journal Procedia Engineering, 192, 342-347. https://doi.org/10.1016/j. proeng.2017.06.059

IAB Spain. (25 de junio de 2015). Estudio de e-Commerce 2015.

Kannan, P. K.; Li, H. (2017). Digital Marketing: a framework, review and research agenda. International Journal of Research in Marketing, 34(1), 22-45. https://doi.org/10.1016/j. ijresmar.2016.11.006

Kotler, P. (2016). Marketing (14a ed.). Naucalpan de Juárez, Estado de México: Pearson.

Kopalle, P. K.; Mela, C. F. (1999). The dynamic effect of discounting of sales: empirical analysis and normative pricing implications, Journal Marketing Science, 18(3), 317-332. DOI: https://doi.org/10.1287/mksc.18.3.317

Londoño, S.; Mora, Y.; Valencia, M. (2018). Modelos estadísticos sobre la eficacia del Marketing digital. Revista Escuela De Administración De Negocios, (84). https://doi. org/10.21158/01208160.n84.2018.1923

Luu, V. T.; Kim, S.-Y.; Huynh, T.-A. (2008). Improving project management performance of large contractors using benchmarking approach. International Journal of Project Management, 26(7), 758-769. DOI: https://doi. org/10.1016/j.ijproman.2007.10.002

Merodio, J. (2016). Estrategia y táctica empresarial en redes sociales. Bogotá: LID Editorial Colombiana.

Nieto, A. (4 de junio de 2016). Las redes sociales más utilizadas por las empresas. Web Empresa 2.0. Recuperado de https://bit. ly/3jzMkIE

Prada, R. (2016). Las TIC, factor de efectividad en la aplicación del mercadeo digital en negocios de retail. Revista Escuela De Administración De Negocios, (80), 105-116. https://doi. org/10.21158/01208160.n80.2016.1460

Ranking de marcas que mejor gestionan sus redes sociales en 2018. (27 de septiembre de 2018). Dinero. Recuperado de https://bit.ly/2QdHq5U

Ramón, E. A.; Segovia, L. C. (2016). Comunicación integrada de Marketing. Madrid: ESIC.

Rojas, J. F. (18 de febrero de 2016). Aburrá Sur necesita desarrollo equilibrado: Cámara de Comercio. El Colombiano. Recuperado de https://bit.ly/2p8uc2d 
Rueda, B. J. (16 de abril de 2017). Cada año se liquidan en Colombia cerca de 140 empresas. El Tiempo. Recuperado de https://bit.ly/2DzKVR3

Smith, M.; Sinha, I. (2000). The impact of price and extra product promotions on store preference. International Journal of Retail \& Distribution, 28(2),83-92. DOI: https://doi. org/10.1108/09590550010315269

Trejos, C. A. (2008). El Marketing directo en la organización en pro de la construcción de marca. Revista de Investigaciones Universidad Católica de Manizales, 12(84). 84-94.

Vila, N.; Küster, I. (2004). Oportunidades y amenazas del e-mail Marketing. Revista Harvard Deusto Marketing y Ventas, 52(1), 66-70

Walpole, R.; Myers, R.; Myers S.; Ye, K. (2012). Probabilidad y estadística para ingeniería y ciencias ( $9^{\mathrm{a}}$ ed.). México: Pearson. 